\title{
Injuries and envenomation by exotic pets in Hong Kong
}

\author{
Vember CH Ng, Albert CH Lit, OF Wong *, ML Tse, HT Fung
}

This article was published on 5 Jan 2018 at www.hkmj.org.

\section{A B S T R A C T}

Introduction: Exotic pets are increasingly popular in Hong Kong and include fish, amphibians, reptiles, and arthropods. Some of these exotic animals are venomous and may cause injuries to and envenomation of their owners. The clinical experience of emergency physicians in the management of injuries and envenomation by these exotic animals is limited. We reviewed the clinical features and outcomes of injuries and envenomation by exotic pets recorded by the Hong Kong Poison Information Centre.

Methods: We retrospectively retrieved and reviewed cases of injuries and envenomation by exotic pets recorded by the Hong Kong Poison Information Centre from 1 July 2008 to 31 March 2017.

Results: There were 15 reported cases of injuries and envenomation by exotic pets during the study period, including snakebite $(\mathrm{n}=6)$, fish sting $(\mathrm{n}=4)$, scorpion sting $(\mathrm{n}=2)$, lizard bite $(\mathrm{n}=2)$, and turtle bite $(n=1)$. There were two cases of major effects from the envenomation, seven cases with moderate effects, and six cases with mild effects. All major effects were related to venomous snakebites. There were no mortalities.

Conclusion: All human injuries from exotic pets arose from reptiles, scorpions, and fish. All cases of major envenomation were inflicted by snakes.

\section{Hong Kong Med J 2018;24:48-55 \\ DOI: $10.12809 / \mathrm{hkmj} 176984$ \\ ${ }^{1}$ VCH Ng, FHKCEM, FHKAM (Emergency Medicine) \\ ${ }^{2}$ ACH Lit, FRCSEd, FHKAM (Emergency Medicine) \\ OF Wong *, FHKAM (Anaesthesiology), FHKAM (Emergency Medicine) \\ ${ }^{1}$ ML Tse, FHKCEM, FHKAM (Emergency Medicine) \\ ${ }^{3}$ HT Fung, FRCSEd, FHKAM (Emergency Medicine) \\ ${ }^{1}$ Hong Kong Poison Information Centre, United Christian Hospital, Kwun Tong, Hong Kong \\ ${ }^{2}$ Accident and Emergency Department, North Lantau Hospital, Tung Chung, Lantau, Hong Kong \\ ${ }^{3}$ Accident and Emergency Department, Tuen Mun Hospital, Tuen Mun, Hong Kong}

* Corresponding author: oifungwong@yahoo.com.hk

New knowledge added by this study

- This is the first case series of injuries and envenomation by exotic pets in Hong Kong.

- Reptiles, scorpions, and fish that are kept as exotic pets can potentially cause injuries to and envenomation of their owners.

- All cases of major envenomation were inflicted by snakes. Envenomation by a highly venomous exotic snake was also encountered.

Implications for clinical practice or policy

- A variety of exotic animals, including venomous species, are kept as pets in Hong Kong. Emergency physicians in Hong Kong, however, have limited knowledge about the management of injuries caused by these exotic animals.

- The Hong Kong Poison Information Centre provides an expert consultation service for the management of injuries and envenomation by such exotic animals.

\section{Introduction}

A variety of exotic animals are kept as 'pets' including fish, amphibians, reptiles, and arthropods. The keeping of exotic, and sometimes venomous pets, is becoming increasingly common worldwide. Some of these exotic pets are capable of causing injury to or even life-threatening envenomation of their owners. ${ }^{1}$

Reptiles are the most popular exotic pets worldwide. It has been estimated that 1.5 to 2.0 million households in the United States (US) own one or more pet reptiles. Snakes account for approximately $11 \%$ of the imported reptiles in the US, and up to $9 \%$ of these are venomous. ${ }^{2}$ Envenomation by exotic pets, particularly snakes, is an increasing cause for concern in both the US and Europe. ${ }^{3}$ In a study of exotic snake envenomation in the US, data from the National Poison Data System database revealed 258 cases of exotic snakebites involving at least 61 unique exotic venomous species between 2005 and 2011. Among these, 40\% of bites occurred in a private residence. ${ }^{4}$ Another study of bites and stings by exotic pets in Europe reported 404 cases in four poison centres in Germany and France from 1996 to 2006. Exotic snakebites from rattlesnakes, cobras, mambas, and other venomous snakes were the cause of approximately $40 \%$ of envenomations. ${ }^{5}$ Another survey conducted in the United Kingdom reviewed the data from the National Health Service 
Health Episode Statistics from 2004 to 2010. A total of 709 hospital admissions associated with injuries from exotic pets were reported and approximately 300 hospital admissions were related to contact with scorpions, venomous snakes, and lizards. ${ }^{6}$ Nonetheless, no such epidemiological study has been conducted in Hong Kong. According to the thematic household survey report in 2006, 286300 households in Hong Kong kept pets at home, of which $5 \%$ were pets other than dogs, cats, turtles, tortoises, birds, hamsters, and rabbits. ${ }^{7}$ The number of imported pet reptiles into Hong Kong has increased rapidly in recent years. In 2016, the Agriculture, Fisheries and Conservation Department (AFCD) recorded that almost 1000000 pet reptiles were imported into Hong Kong (Table 1).

The knowledge of local emergency physicians about the management of injuries by these exotic animals is limited. Since 2005, the Hong Kong Poison Information Centre (HKPIC) has provided a 24-hour telephone consultation service (tel: 26351111) for health care professionals in Hong Kong, offering poison information and clinical management advice. The objectives of this study were to use HKPIC records to describe the variety of reported exotic species and the clinical features and outcomes of injuries and envenomation caused by exotic pets.

\section{Methods}

This was a case series based on the database of the HKPIC. It included cases encountered by clinical frontline staff and surveillance data from routine reporting of poisoning cases by all accident and emergency departments (AEDs) under the Hospital Authority (HA). Cases of injuries and envenomation by exotic pets recorded by the HKPIC from 1 July 2008 to 31 March 2017 were retrospectively retrieved. Demographic data of the patients-including the involved species, clinical presentations, and outcomes-were reviewed from the patient electronic health record. This study was done in accordance with the principles outlined in the Declaration of Helsinki.

The severity of injuries and the effects of envenomation were defined as major (lifethreatening or resulting in significant residual disability or disfigurement), moderate (pronounced, prolonged, or systemic signs and symptoms), or mild (minimal and rapidly resolving signs and symptoms).

\section{Results}

During the study period, 15 cases of injuries and envenomation by exotic pets were reported to the HKPIC. Among the 15 patients, nine consulted the HKPIC for management advice and one was managed by the toxicology team of the AED. Local zoologists were consulted in five cases for species

\section{在香港被另類寵物蟄傷或刺傷的情況}

黃俊豪、列就雄、黄凱峯、謝萬里、馮顯達

引言：另類寵物在香港越來越受歡迎, 包括魚、兩棲類、爬行動物和 節肢動物。當中部分是有毒的, 可能會蟄傷或刺傷飼養者。急症室醫 生處理這些病例的臨床經驗很有限。我們回顧了香港中毒諮詢中心 內, 被這些另類寵物蟄傷或刺傷的有關病例, 研究其臨床特徵和治理 結果。

方法：我們回顧了2008年7月1日至2017年3月31日期間，香港中毒諮 詢中心收到被另類寵物蟄傷或刺傷的病例。

結果：研究期間共有 15 宗相關的病例報告, 包括被蛇咬 6 例、魚蟄4 例、蠍蟄 2 例、蚚蜴咬 2 例和龜咬 1 例。有 2 例有嚴重後果, 7 例影響 屬中度, 另有 6 例影響輕微。所有嚴重後果的病例均與被毒蛇咬傷有 關。研究期間並無死亡個案。

結論：另類寵物對人的傷害均來自爬行動物、蟩子和魚類。所有嚴重 後果的病例均與毒蛇咬傷有關。

identification and opinion about the venomous nature of the species. All bites and stings were unintentional and occurred in a private household. The mean age of the exotic pet owners was 28.2 (range, 14-59) years and the majority (73\%) were male. There were six cases of snakebite, four cases of fish sting, two cases of scorpion sting, two cases of lizard bite, and one case of turtle bite. The severity of injury and envenomation effect are summarised in Table 2.

All major effects occurred in patients with snakebite. A 16-year-old boy was bitten by a short-

TABLE I. Number of imported pet reptiles in Hong Kong from 2012 to 2016 (data from the Agriculture, Fisheries and Conservation Department)

\begin{tabular}{lc}
\hline Year & No. of imported pet reptiles (heads) ${ }^{*}$ \\
\hline 2016 & 997000 \\
2015 & 826000 \\
2014 & 880000 \\
2013 & 569000 \\
2012 & 470000 \\
\hline
\end{tabular}

* Figures are rounded to the nearest thousand

TABLE 2. Severity of injury and envenomation effect caused by exotic pets

\begin{tabular}{lcccc}
\hline \multirow{2}{*}{$\begin{array}{l}\text { Type of bite or } \\
\text { sting }\end{array}$} & \multicolumn{4}{c}{ No. of cases } \\
\cline { 2 - 5 } & $\begin{array}{c}\text { Major } \\
\text { effects }\end{array}$ & $\begin{array}{c}\text { Moderate } \\
\text { effects }\end{array}$ & $\begin{array}{c}\text { Mild } \\
\text { effects }\end{array}$ & Total \\
\hline Snakebite & 2 & 3 & 1 & 6 \\
\hline Fish sting & - & 3 & 1 & 4 \\
\hline Lizard bite & - & 1 & 1 & 2 \\
\hline Scorpion sting & - & - & 2 & 2 \\
\hline Turtle bite & - & - & 1 & 1 \\
\hline
\end{tabular}


tailed mamushi (Gloydius blomhoffii brevicaudus; Fig 1a) on his left middle finger. The short-tailed mamushi is not native to Hong Kong but was being kept as a pet. The patient had a history of snakebite by a bamboo snake (Trimeresurus albolabris) that required antivenom treatment, sustained while attempting to catch the snake in the suburbs. Following the bite by the short-tailed mamushi, the patient developed severe local envenomation over his left hand and required admission to the intensive care unit for close observation of the rapidly progressing local envenomation. No systemic envenomation was observed. A local zoologist was consulted for snake identification. A total of three vials of antivenom for Agkistrodon halys were administered as treatment but ischaemia due to compartment syndrome developed in the left hand. Debridement and fasciotomy were eventually performed. The patient had a residual flexion contraction deformity of his left middle finger 2 months later. He recovered with full movement of the left middle finger 6 months after the injury. Another boy, aged 15 years, was bitten by a bamboo snake on his left thumb. The snake had been caught by the patient in the suburbs and kept as a pet. He developed severe local envenomation and was given three vials of antivenom for Agkistrodon halys and three vials of antivenom for green pit viper. The patient developed tenosynovitis of his left thumb and required emergency surgery for debridement. Another four patients were bitten by 'nonvenomous' snakes including a rainbow boa (Epicrates cenchria; Fig 1b), corn snake (Pantherophis guttatus), and eastern hognose snake (Heterodon platirhinos; Fig 1c). All snakes were kept as pets. An 18-year-old girl was accidentally bitten by a rainbow boa on her left hand but had no signs of local or systemic envenomation after the injury. Another patient developed a wound infection after being bitten by a corn snake 2 weeks previously (Fig 1d). She recovered after a course of antibiotic therapy. Two young men were bitten by hognose snakes. One developed local envenomation with progressive swelling over the injured hand (Fig 1e). The local envenomation resolved with conservative management. The HKPIC was consulted in all cases, of which three required consultation with a zoologist.

Injuries from reptiles other than snakes were also recorded. There were two cases of lizard bite. In one case, a 22-year-old man was bitten by a common iguana (Iguana iguana) on his left wrist. In the other case, a 41-year-old man presented to the AED approximately 2 hours after being bitten on his right hand by a Gila monster (Fig 2a). He developed intense pain and local swelling over the site of injury. The pain lasted for about 12 hours and then gradually improved. His haemodynamic state remained stable and no airway oedema or neurological symptoms were observed during his stay in the emergency medicine ward. He was eventually discharged. A young woman attended the AED because of a

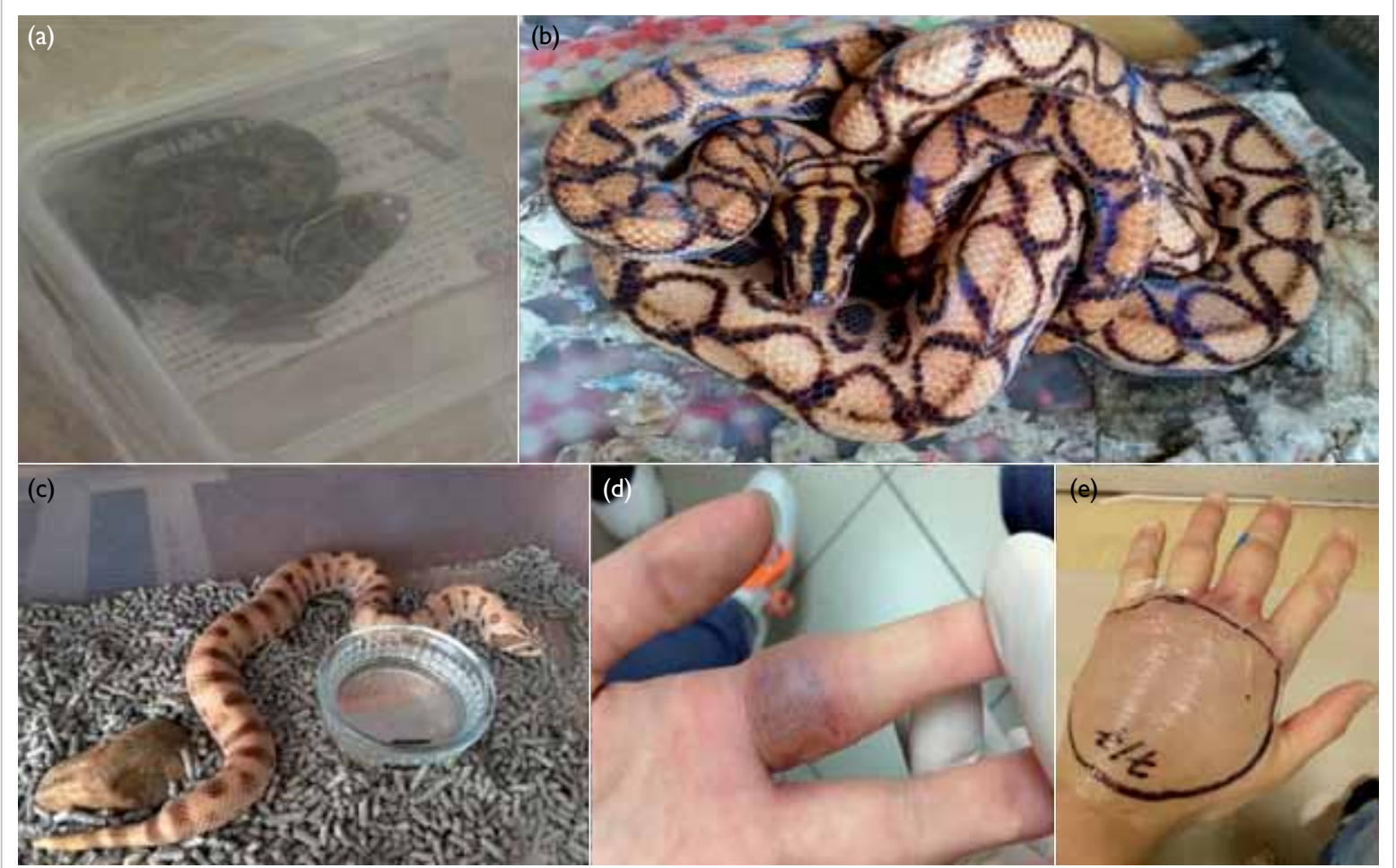

FIG I. (a) Short-tailed mamushi (Gloydius blomhoffii brevicaudus), (b) rainbow boa (Epicrates cenchria), and (c) eastern hognose snake (Heterodon platirhinos). (d) Local wound infection after being bitten by a corn snake (Pantherophis guttatus), and (e) local envenomation after a bite by an eastern hognose snake 

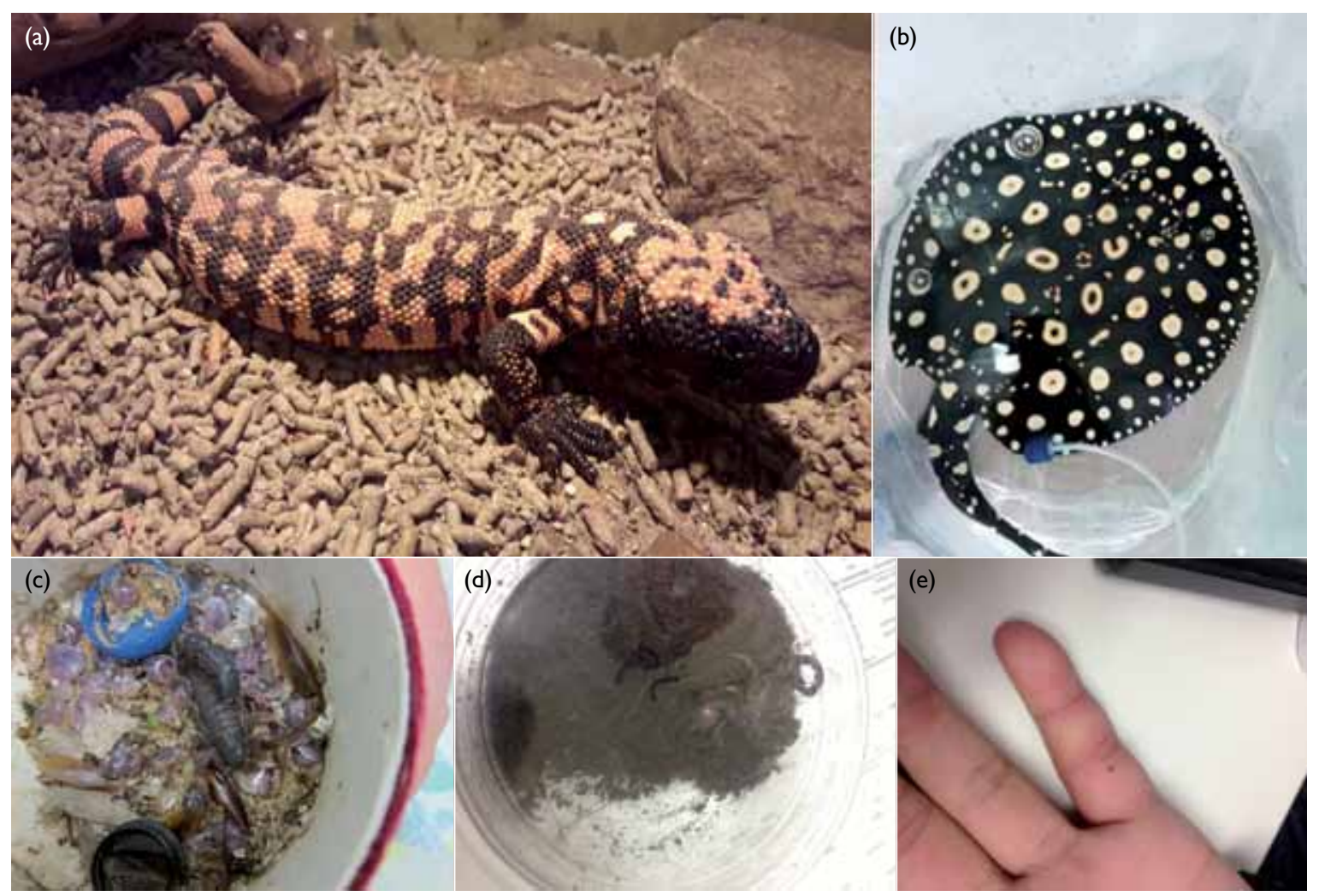

FIG 2. (a) Gila monster (Heloderma suspectum) and (b) freshwater stingray (Potamotrygon species). (c) Thick-tailed scorpion (Parabuthus transvaalicus) and (d) cave-claw scorpion (Pandinus cavimanus). (e) Wound infection after cave-claw scorpion sting

turtle bite over her left face with consequent minor physical injury.

Stings by aquarium fish were the second most common injuries by exotic pets. Four cases were recorded, including one sting by a blue tang fish and three by freshwater stingrays (Fig 2b). All patients developed severe pain over the site of injury that responded to immersion in hot water. One of the patients with a freshwater stingray sting developed a wound infection that required emergency surgery for wound exploration and irrigation.

Two male patients were stung by their pet scorpions: a thick-tailed scorpion (Parabuthus transvaalicus; Fig 2c) and a cave-claw scorpion (Pandinus cavimanus; Fig 2d). No systemic envenomation was observed. The patient with the cave-claw scorpion sting developed a local wound infection (Fig 2e) that recovered after a course of antibiotics.

The characteristics and management of the 15 cases are summarised in Table 3.

\section{Discussion}

Injuries by a variety of exotic pets were encountered in this study. More than half of the injuries (9/15) were inflicted by reptiles. Reptiles are becoming increasingly popular to keep as pets in Hong Kong.
According to the records of the AFCD over the past 5 years, the top 10 most common reptile species imported to Hong Kong are the European pond turtle (Emys orbicularis), razor-backed musk turtle (Sternotherus carinatus), common snapping turtle (Chelydra serpentina), red-bellied cooter (Pseudemys nelsoni), yellow-spotted Amazon River turtle (Podocnemis unifilis), Hermann's tortoise (Testudo hermanni), African spurred tortoise (Geochelone sulcata), leopard tortoise (Stigmochelys pardalis), common iguana (Iguana iguana), and ball python (Python regius). Commonly imported pet snakes include the ball python (Python regius), king snake (Lampropeltis getula), corn snake (Pantherophis guttatus), rat snake (Elaphe obsoleta), milk snake (Lampropeltis triangulum), and western hognose snake (Heterodon nasicus). With the exception of the hognose snake, which is a mildly venomous species, they are all nonvenomous. Nonetheless, a much wider variety of species, including venomous reptiles, may be sold on the black market. Bites may occur during the care and handling of these exotic animals. ${ }^{3}$ Envenomation by exotic venomous species is an uncommon but often serious medical emergency.

The keeping of venomous snakes is common in the US. ${ }^{4}$ Amateur collectors are at risk of bites and envenomation and fatalities have been reported. ${ }^{8}$ 
TABLE 3. Detailed description of 15 reported cases of injuries and envenomation by exotic pets

\begin{tabular}{|c|c|c|c|c|c|c|c|c|}
\hline \multirow[t]{2}{*}{ Case No. } & \multirow{2}{*}{$\begin{array}{l}\text { Patient } \\
\text { age } \\
\text { (years) }\end{array}$} & \multirow{2}{*}{$\begin{array}{l}\text { Sex } \\
(M / F)\end{array}$} & \multicolumn{2}{|c|}{ Involved species } & \multirow[t]{2}{*}{ Antivenom } & \multirow[t]{2}{*}{ Surgery } & \multirow{2}{*}{$\begin{array}{c}\text { HKPIC/ } \\
\text { toxicology } \\
\text { team } \\
\text { consultation }\end{array}$} & \multirow{2}{*}{$\begin{array}{l}\text { Zoologist } \\
\text { consultation }\end{array}$} \\
\hline & & & Common name & Scientific name & & & & \\
\hline \multicolumn{9}{|l|}{ Snakebites } \\
\hline 1 & 16 & $\mathrm{M}$ & Short-tailed mamushi & $\begin{array}{l}\text { Gloydius blomhoffii } \\
\text { brevicaudus }\end{array}$ & Yes & Yes & Yes & Yes \\
\hline 2 & 18 & $\mathrm{~F}$ & Rainbow boa & Epicrates cenchria & No & No & Yes & Yes \\
\hline 3 & 15 & $\mathrm{M}$ & Bamboo snake & Trimeresurus albolabris & Yes & Yes & Yes & No \\
\hline 4 & 17 & $\mathrm{~F}$ & Corn snake & Pantherophis guttatus & No & No & Yes & No \\
\hline 5 & 24 & $\mathrm{M}$ & Eastern hognose snake & Heterodon platirhinos & No & No & Yes & Yes \\
\hline 6 & 25 & $\mathrm{M}$ & Eastern hognose snake & Heterodon platirhinos & No & No & Yes & No \\
\hline \multicolumn{9}{|l|}{ Fish stings } \\
\hline 7 & 32 & $\mathrm{M}$ & Blue tang fish & Paracanthurus hepatus & No & No & No & No \\
\hline 8 & 41 & $\mathrm{M}$ & Fresh water stingray & Potamotrygon sp & No & No & No & No \\
\hline 9 & 43 & $\mathrm{M}$ & Fresh water stingray & Potamotrygon sp & No & Yes & No & No \\
\hline 10 & 59 & $\mathrm{~F}$ & Fresh water stingray & Potamotrygon sp & No & No & No & No \\
\hline \multicolumn{9}{|c|}{ Scorpion stings } \\
\hline 11 & 29 & $\mathrm{M}$ & Thick-tailed scorpion & Parabuthus transvaalicus & No & No & Yes & Yes \\
\hline 12 & 14 & $\mathrm{M}$ & Cave-claw scorpion & Pandinus cavimanus & No & No & Yes & Yes \\
\hline \multicolumn{9}{|c|}{ Lizard bites } \\
\hline 13 & 22 & $\mathrm{M}$ & Common iguana & Iguana iguana & No & No & Yes & No \\
\hline 14 & 41 & $M$ & Gila monster & Heloderma suspectum & No & No & Yes & No \\
\hline \multicolumn{9}{|l|}{ Turtle bite } \\
\hline 15 & 27 & $\mathrm{~F}$ & Turtle & Unknown & No & No & No & No \\
\hline
\end{tabular}

Abbreviation: HKPIC = Hong Kong Poison Information Centre

Although envenomation from exotic snakes is rarely encountered in Hong Kong, it poses a great challenge to emergency physicians owing to their lack of experience and limited supplies of antivenom, as illustrated by our case of bite by a short-tailed mamushi. Currently, the HA stocks principally snake antivenom for local venomous species (Table 4). Bites by nonvenomous pet snakes may also result in local envenomation and complications; for instance, although the hognose snake is known as a nonvenomous species, one patient developed local envenomation after being bitten. Another patient developed a wound infection after being bitten by a corn snake.

As well as snakes, lizards are popular as pets. Bites by large species such as the common green iguana (Iguana iguana) can result in serious injury. ${ }^{9}$ Envenomation from lizard bites is rare in Hong Kong. Two lizards are well known to be venomous: the Gila monster (Heloderma suspectum) ${ }^{10}$ and the Mexican beaded lizard (Heloderma horridum). ${ }^{11,12}$ Both have venom-secreting glands and bites. The Gila monster is native to the southwestern US extending into Mexico, whereas the beaded lizard is native only to Mexico. The Gila monster is listed in the Convention on International Trade in
Endangered Species of Wild Fauna and Flora (CITES) as a protected species..$^{13}$ Captive-bred Gila monsters are traded in international pet markets. Venom of the Gila monster consists of a variety of proteins including gilatoxin, a kallikrein-like protease that can hydrolyse kininogen and produce bradykinin..$^{11,14}$ The common envenomation effects are intense pain at the injured site, oedema, paraesthesia, weakness, dizziness, and nausea. Hypotension occurs in severe envenomation..$^{15}$ The intense pain, oedema, and hypotension are likely due to the bradykininmediated effects. Airway oedema has been reported regardless of the site of bite and may occur up to 12 hours after the bite. ${ }^{14}$ Nevertheless, severe envenomation from the Gila monster occurs in only a minority of patients. In a retrospective study of all cases of Gila monster bite reported to the two Arizona poison control centres from 2000 to 2011, 105 cases of human exposure to Gila monsters were recorded and 70 cases were referred to health care facilities for medical treatment. Eleven cases required admission to hospital and five required care in an intensive care unit. Six patients developed airway oedema and three required emergent airway management including one cricothyrotomy.$^{14}$ Treatment of Gila monster bites is mainly supportive. Intravenous crystalloid infusion 
TABLE 4. Antivenoms currently available in the Hong Kong Poison Information Centre and public hospitals under the Hospital Authority

\begin{tabular}{|c|c|}
\hline Antivenom & Target species in clinical practice \\
\hline \multicolumn{2}{|l|}{ Snake antivenoms } \\
\hline Bungarus fasciatus & Banded krait (Bungarus fasciatus) \\
\hline Green pit viper & White-lipped pit viper/bamboo snake (Trimeresurus albolabris) \\
\hline Bungarus multicinctus and Naja naja atra & Many-banded krait (Bungarus multicinctus) and Chinese cobra (Naja atra) \\
\hline Agkistrodon acutus & Sharp-nosed pit viper/hundred pacer/Chinese moccasin (Deinagkistrodon acutus) \\
\hline King cobra & King cobra (Ophiophagus hannah) \\
\hline Russell's viper & Russell's viper (Daboia russelii) \\
\hline Tiger snake & Sea snake species \\
\hline Trimeresurus mucrosquamatus and Trimeresurus gramineus & Chinese habu (Trimeresurus mucrosquamatus) and bamboo snake \\
\hline \multicolumn{2}{|l|}{ Other antivenoms } \\
\hline Scorpifav (Sanofi Pasteur, France) & Scorpion species: Androctonus australis, Buthus occitanus, Leiurus quinquestriatus \\
\hline Stone fish & Stone fish \\
\hline
\end{tabular}

and vasopressors may be required for treatment of hypotension in severe envenomation. Radiographic assessment is needed to look for retained teeth and subcutaneous air due to the chewing-like action during the bites. ${ }^{16}$ No antivenom to Gila monster is commercially available. ${ }^{17}$ Observation for at least 12 hours after the bite for delayed-onset airway oedema is recommended. ${ }^{14}$

Among all the reptiles, tortoises and turtles are the most popular in pet markets. All species of tortoises and turtles are nonvenomous although some, such as the alligator snapping turtle (Macrochelys temminckii) and the common snapping turtle (Chelydra serpentina), are aggressive and can grow to a very large size. Bites by these large species can result in severe limb injuries. ${ }^{18}$

Stings by aquarium fish contributed to the second largest group of injuries in our case series. The most commonly encountered aquarium fish was freshwater stingray. Freshwater stingrays (Potamotrygon species) are native to South America. They are regarded as dangerous by the native people of the Amazon and frequent sting during fishing season. ${ }^{19}$ Freshwater stingrays are not aggressive by nature; stings frequently occur when people step on them or handle them improperly. Different species of freshwater stingrays have different colour patterns on their body. They are popular aquarium fish as they are easy to keep although stings may result in severe envenomation. ${ }^{20}$ The most common feature of envenomation from freshwater stingrays is intense local pain. Systemic manifestations are rare. Skin necrosis is frequently observed in victims wounded by large freshwater stingrays in the wild. ${ }^{21}$ In addition, skin necrosis is more commonly observed in victims injured by freshwater stingrays than marine stingrays. A study of tissue extracts from the stingers of freshwater and marine stingrays showed that both tissue extracts had gelatinolytic, caseinolytic, and fibrinogenolytic activity but hyaluronidase activity was detected only in the extracts from freshwater stingrays. ${ }^{22}$ In our case series, no patient injured by a freshwater stingray developed skin necrosis. The risk of developing skin necrosis is likely related to the venom load. Larger stingrays possess a much larger venom load in their stingers. Small freshwater stingrays are commonly kept in an aquarium and skin necrosis as a result of their sting is uncommon. Hot water immersion is effective in controlling acute pain but does not prevent skin necrosis. ${ }^{21}$ Wounds caused by freshwater stingray stings such as the Aeromonas species can be complicated by severe secondary infection with virulent bacteria. ${ }^{23}$ Prophylactic antibiotic is often required.

Apart from freshwater stingrays, the stinging catfish (Heteropneustes fossilis) is another commonly reported freshwater aquarium fish that can cause injuries and envenomation. It possesses venom in the sting that is located in front of the soft-rayed portion of the pectoral and dorsal fins. Apart from intense local pain, systemic envenomation including weakness and hypotension can result from a sting. ${ }^{24,25}$ There was no case reported to the HKPIC of injury by this venomous catfish during the study period. Coral reef fish are also popular pets in Hong Kong. Some coral reef fish, such as the lionfish (Pterois volitans), are venomous. ${ }^{26}$ Nonetheless, injuries by aquarium coral reef fish were rarely encountered in the AED of Hong Kong.

Exotic pet owners also enjoy keeping arthropods such as scorpions and spiders. There are approximately 2000 species of scorpion in the world but only a few (30 to 40) are highly venomous and able to cause severe envenomation in humans. ${ }^{27}$ Scorpion envenomation is reported throughout the world, mainly in subtropical and tropical regions. ${ }^{28}$ The majority of scorpion stings cause mild or no envenomation. Species that cause serious medical problems mainly belong to the Buthidae family. The genera of the Buthidae family include 
Centruroides, Tityus, Leiurus, Androctonus, Buthus and Parabuthus. ${ }^{29}$ Scorpions have a special venom apparatus, the telson, that produces venom. Scorpion venom comprises numerous toxins including several neurotoxins. Unlike snake venom, scorpion venom generally lacks enzyme activity. The main molecular targets of scorpion neurotoxins are the voltage-gated sodium channels and the voltage-gated potassium channels. Scorpion $\alpha$-toxin, one of the most medically important neurotoxins in the scorpion venom, acts on the voltage-gated sodium channels. Once the toxin binds to voltage-gated sodium channels, it inhibits inactivation of the channel with consequent prolonged depolarisation and, hence, neuronal excitation. The autonomic centres, both sympathetic and parasympathetic, are stimulated. In most situations of scorpion envenomation, the sympathetic nerves are predominantly affected. Scorpion envenomation is characterised by relatively similar neurotoxic excitation syndromes, irrespective of the species. Parasympathetic effects tend to occur early and then sympathetic effects persist due to the release of catecholamines that are responsible for the severe envenomation. Parasympathetic (cholinergic) effects include hypersalivation, diaphoresis, lacrimation, miosis, diarrhoea, vomiting, bradycardia, hypotension, increased respiratory secretion, and priapism. Sympathetic (adrenergic) effects are manifested as tachycardia, hypertension, mydriasis, hyperthermia, hyperglycaemia, and agitation. Fatal effects of scorpion envenomation are largely due to cardiovascular effects. Various cardiac conduction abnormalities have been reported in patients with scorpion envenomation as well as catecholamine-induced cardiomyopathy, pulmonary oedema, and cardiogenic shock. Other manifestations of systemic envenomation include vomiting, abdominal pain, abnormal oculomotor movements, muscle fasciculation, and spasms of the face and limbs. ${ }^{29}$ Pancreatitis is also a well-reported complication of envenomation by certain species, such as Leiurus quinquestriatus. ${ }^{30}$ Nonetheless, severe local envenomation is generally uncommon. Differences in the clinical manifestations of systemic envenomation exist in some species. Delayed localised necrosis has been reported in patients stung by an Iranian scorpion (Hemiscorpius lepturus). ${ }^{31}$ Patients with envenomation from the thick-tailed scorpion (Parabuthus transvaalicus) in Zimbabwe have been reported to develop predominant symptoms from parasympathetic nerve system stimulation, including profuse sialorrhoea, sweating, and urinary retention, in the absence of sympathetic stimulation. $^{32}$

Scorpion stings and envenomation are uncommon in Hong Kong. Most of the locally reported cases of scorpion sting occurred while patients were handling langsat, a type of tropical fruit from South-East Asia. The Chinese stropped bark scorpion (Lychas mucronatus) hides in the fruit and is subsequently imported into Hong Kong. ${ }^{33}$ Scorpions are also sold as fish food in aquarium shops in Hong Kong. People use scorpions to feed arowana, which are popular aquarium fish. Importation of endangered scorpion species (CITESlisted species) for commercial purposes is regulated by the Protection of Endangered Species of Animals and Plants Ordinance Cap. 586 in Hong Kong. ${ }^{34}$ According to the data from the AFCD for importation of CITES-listed scorpions, more than 1000 heads of emperor scorpion (Pandinus imperator) have been imported as pets to Hong Kong each year for the last 4 years. The emperor scorpion is a nonvenomous species and is native to the rainforests and savannas of West Africa. Most scorpions in the pet trade, such as the forest scorpion (Heterometrus species), have no potential for dangerous envenomation. Nonetheless venomous species may also be kept by hobbyists and severe envenomation may occur after stings.

Management of scorpion stings includes local wound care and supportive care for systemic envenomation. Expert opinion should be sought from a zoologist for species identification and to determine the venomous nature of the species. Patients with severe systemic envenomation may require antivenom therapy. Specific antivenom (Scorpifav; Sanofi Pasteur, France) for Androctonus australis, Buthus occitanus, and Leiurus quinquestriatus is currently available in the HKPIC.

Spiders, such as tarantulas, are popular exotic pets and are common in the pet trade in Hong Kong. Nonetheless, inexperienced owners may be unaware of the potential risk of ocular injury from the barbed urticating hairs on the abdomen of the tarantulas. Eye injuries occur when the barbed hairs come into contact with the eyes, either directly from the tarantula's ejection or when the owners rub their eyes after handling the spider. ${ }^{35}$ Embedment of the hairs in the cornea can result in severe complications, including ophthalmia nodosa, iritis, and even permanent visual impairment. ${ }^{36,37}$

\section{Conclusion}

The diversity of pets is changing and keeping exotic animals is increasingly popular. Injuries from these exotic pets are expected to increase and envenomation may result from stings or bites from some species. In our case series, reptiles, scorpions, and fish were responsible for human injuries, and all cases of major envenomation were inflicted by snakes. Emergency physicians need to be aware of the appropriate management of injuries and envenomation by these exotic animals. The HKPIC plays an important role in the provision of expert advice about management of these special toxicological cases. 


\section{Acknowledgement}

The authors would like to thank AFCD for providing the data of imported reptiles, scorpions, and spiders.

\section{Declaration}

All authors have disclosed no conflicts of interest.

\section{References}

1. Bey TA, Boyer LV, Walter FG, McNally J, Desai H. Exotic snakebite: envenomation by an African puff adder (Bitis arietans). J Emerg Med 1997;15:827-31.

2. McNally J, Boesen K, Boyer L. Toxicologic information resources for reptile envenomations. Vet Clin North Am Exot Anim Pract 2008;11:389-401.

3. de Haro L, Pommier P. Envenomation: a real risk of keeping exotic house pets. Vet Hum Toxicol 2003;45:214-6.

4. Warrick BJ, Boyer LV, Seifert SA. Non-native (exotic) snake envenomations in the U.S., 2005-2011. Toxins (Basel) 2014;6:2899-911.

5. Schaper A, Desel H, Ebbecke M, et al. Bites and stings by exotic pets in Europe: an 11 year analysis of 404 cases from Northeastern Germany and Southeastern France. Clin Toxicol (Phila) 2009;47:39-43.

6. Warwick C, Steedman C. Injuries, envenomations and stings from exotic pets. J R Soc Med 2012;105:296-9.

7. Thematic household survey report 2006. Census and Statistics Department, HKSAR Government. Available from: http://www.statistics.gov.hk/pub/ B11302262006XXXXB0100.pdf. Accessed 1 Jun 2017.

8. Marsh N, DeRoos F, Touger M. Gaboon viper (Bitis gabonica) envenomation resulting from captive specimens-a review of five cases. Clin Toxicol (Phila) 2007;45:60-4.

9. Heffelfinger RN, Loftus P, Cabrera C, Pribitkin EA. Lizard bites of the head and neck. J Emerg Med 2012;43:627-9.

10. Hooker KR, Caravati EM, Hartsell SC. Gila monster envenomation. Ann Emerg Med 1994;24:731-5.

11. Cantrell FL. Envenomation by the Mexican beaded lizard: a case report. J Toxicol Clin Toxicol 2003;41:241-4.

12. Ariano-Sánchez D. Envenomation by a wild Guatemalan beaded lizard Heloderma horridum charlesbogerti. Clin Toxicol (Phila) 2008;46:897-9.

13. Wijnstekers W. The Convention on International Trade in Endangered Species of Wild Fauna and Flora (CITES) - 35 years of global efforts to ensure that international trade in wild animals and plants is legal and sustainable. Forensic Sci Rev 2011;23:1-8.

14. French R, Brooks D, Ruha AM, et al. Gila monster (Heloderma suspectum) envenomation: descriptive analysis of calls to United States Poison Centers with focus on Arizona cases. Clin Toxicol (Phila) 2015;53:60-70.

15. Piacentine J, Curry SC, Ryan PJ. Life-threatening anaphylaxis following gila monster bite. Ann Emerg Med 1986;15:959-61.

16. French RN, Ash J, Brooks DE. Gila monster bite. Clin Toxicol (Phila) 2012;50:151-2.

17. Miller MF. Gila monster envenomation. Ann Emerg Med 1995;25:720.

18. Johnson RD, Nielsen CL. Traumatic amputation of finger from an alligator snapping turtle bite. Wilderness Environ Med 2016;27:277-81.

19. Junior VH, Cardoso JL, Neto DG. Injuries by marine and freshwater stingrays: history, clinical aspects of the envenomations and current status of a neglected problem in Brazil. J Venom Anim Toxins Incl Trop Dis 2013;19:16.

20. Brisset IB, Schaper A, Pommier P, de Haro L. Envenomation by Amazonian freshwater stingray Potamotrygon motoro: 2 cases reported in Europe. Toxicon 2006;47:32-4.

21. Haddad V Jr, Neto DG, de Paula Neto JB, de Luna Marques FP, Barbaro KC. Freshwater stingrays: study of epidemiologic, clinic and therapeutic aspects based on 84 envenomings in humans and some enzymatic activities of the venom. Toxicon 2004;43:287-94.

22. Barbaro KC, Lira MS, Malta MB, et al. Comparative study on extracts from the tissue covering the stingers of freshwater (Potamotrygon falkneri) and marine (Dasyatis guttata) stingrays. Toxicon 2007;50:676-87.

23. Polack FP, Coluccio M, Ruttimann R, Gaivironsky RA, Polack NR. Infected stingray injury. Pediatr Infect Dis J 1998;17:349,360.

24. Dorooshi G. Catfish stings: a report of two cases. J Res Med Sci 2012;17:578-81.

25. Satora L, Kuciel M, Gawlikowski T. Catfish stings and the venom apparatus of the African catfish Clarias gariepinus (Burchell, 1822), and stinging catfish Heteropneustes fossilis (Bloch, 1794). Ann Agric Environ Med 2008;15:163-6.

26. Chan HY, Chan YC, Tse ML, Lau FL. Venomous fish sting cases reported to Hong Kong Poison Information Centre: a three-year retrospective study on epidemiology and management. Hong Kong J Emerg Med 2010;17:40-4.

27. Santos MS, Silva CG, Neto BS, et al. Clinical and epidemiological aspects of scorpionism in the world: a systematic review. Wilderness Environ Med 2016;27:504-18.

28. Chippaux JP, Goyffon M. Epidemiology of scorpionism: a global appraisal. Acta Trop 2008;107:71-9.

29. Kounis NG, Soufras GD. Scorpion envenomation. N Engl J Med 2014;371:1558-9.

30. Sofer S, Shalev H, Weizman Z, Shahak E, Gueron M. Acute pancreatitis in children following envenomation by the yellow scorpion Leiurus quinquestriatus. Toxicon 1991;29:125-8.

31. Pipelzadeh MH, Jalali A, Taraz M, Pourabbas R, Zaremirakabadi A. An epidemiological and a clinical study on scorpionism by the Iranian scorpion Hemiscorpius lepturus. Toxicon 2007;50:984-92.

32. Bergman NJ. Scorpion sting in Zimbabwe. S Afr Med J 1997;87:163-7.

33. Centre for Food Safety, Hong Kong SAR Government. Scorpion stings and langsat. Food Safety Focus (16th Issue, Nov 2007). Available from: http://www.cfs.gov.hk/english/ multimedia/multimedia_pub/multimedia_pub_fsf_16_04. html. Accessed 1 Jun 2017.

34. Agriculture, Fisheries and Conservation Department, Hong Kong SAR Government. Protection of Endangered Species of Animals and Plants Ordinance. Available from: http://www.afcd.gov.hk/english/conservation/con_end/ con_end_reg/con_end_reg_ord/con_end_reg_ord.html. Accessed 1 Jun 2017.

35. Waggoner TL, Nishimoto JH, Eng J. Eye injury from tarantula. J Am Optom Assoc 1997;68:188-90.

36. Belyea DA, Tuman DC, Ward TP, Babonis TR. The red eye revisited: ophthalmia nodosa due to tarantula hairs. South Med J 1998;91:565-7.

37. Blaikie AJ, Ellis J, Sanders R, MacEwen CJ. Eye disease associated with handling pet tarantulas: three case reports. BMJ 1997;314:1524-5. 